\title{
Design of experiment analysis of elevated temperature wear of Mg-WC nano-composites
}

\author{
Sudip Banerjee ${ }^{1}$, Goutam Sutradhar ${ }^{2}$, Prasanta Sahoo ${ }^{3}$ \\ ${ }^{1}$ Department of Mechanical Engineering, Jadavpur University, Kolkata, India, e-mail: banerjeesudip71@ gmail.com \\ ${ }^{2}$ National Institute of Technology, Manipur, India, e-mail: cast_1963@ rediffmail.com \\ ${ }^{3}$ Department of Mechanical Engineering, Jadavpur University, Kolkata, India, e-mail: psjume @ gmail.com
}

\section{Article Info \\ Article history: \\ Received Jun 23, 2021 \\ Revised September 20, 2021 \\ Accepted October 1, 2021}

\section{Keywords:}

Magnesium,

Nano-composites,

Taguchi methodology,

S/N Ratio,

Wear.

\begin{abstract}
Current study explores the effect of selected process parameters i.e. wt.\% of reinforcement (A), elevated temperature (B) and load (C) on wear characteristics of $\mathrm{Mg}-\mathrm{WC}$ nanocomposites using Taguchi robust design concept. Ultrasonic treated stir casting is employed to synthesize nanocomposites. Three levels for every factor are taken into consideration and accordingly $\mathrm{L}_{27}$ orthogonal array $(\mathrm{OA})$ is used for minimization of wear rate. Main effect plot is generated to investigate the important parameters and optimality is also predicted from the main effect plot. Optimal condition for minimum wear rate is $2 \mathrm{wt} . \%$ of $\mathrm{WC}, 100^{\circ} \mathrm{C}$ temperature and $20 \mathrm{~N}$ load (A3B1C1). Interaction plots are generated to scrutinize the interaction outcome between selected parameters. ANOVA study is executed to evaluate significant parameters and their effective handout on output. Current investigation reveals, Wt.\% of WC is the most significant factor while temperature and load are moderately significant. Among the interacting parameters, interaction between wt.\% of WC \& temperature $(\mathrm{A} \times \mathrm{B})$ has moderate significance. Wt. $\%$ of WC (A) has $43.135 \%$ contribution while temperature (B), load $(\mathrm{C})$ and interaction between wt.\% of WC \& temperature $(\mathrm{A} \times \mathrm{B})$ have $26.623 \%, 19.037 \%$ and $5.639 \%$ contribution respectively. Residual plots for wear rate are discussed and confirmation test finally helps to validate present experimental model. $\mathrm{S} / \mathrm{N}$ ratio is improved by $4.411 \mathrm{~dB}$ (48.60\%) than the initial condition.
\end{abstract}

Copyright (C) 2021 Regional Association for Security and crisis management and European centre for operational research. All rights reserved.

\section{Corresponding Author:}

Prasanta Sahoo,

Department of Mechanical Engineering, Jadavpur University, Kolkata-700032, India.

Email: psjume@gmail.com

\section{Introduction}

Need of lightweight materials for aviation and automotive industries are continuously increasing due to the concern of fuel consumption and hazardous emissions (Hirsch \& Al-Samman, 2013). Particularly magnesium alloys are becoming suitable choice of aviation and automotive industries due to their light weight (two third of $\mathrm{Al}$ ), good machinability ( $<50 \%$ than $\mathrm{Al}$ ) and better manufacturability $(<25-50 \%$ than $\mathrm{Al}$ ) (Avedesian \& Baker, 1999). But typical applications of magnesium alloys are restricted due to low modulus, inherent brittleness, lower strength at elevated temperature and poor high temperature tribological performance. Hence applications of $\mathrm{Mg}$ alloys are restricted in certain specific elevated temperature applications like engine parts $\left(\sim 200^{\circ} \mathrm{C}\right)$, bearing of aerospace, IC engines $\left(\sim 175^{\circ} \mathrm{C}\right)$ and cylinder liners (Pai et al., 2012). Hence researchers are focusing towards improvement of properties of magnesium alloys so that their application areas become wider. Presently, scientific community is considering several methods like use of rare earth (RE) element as alloying element, use of ceramic particles as reinforcement (Banerjee et al., 2019). Zafari et al. (2012) have examined wear characteristics of AZ91 magnesium alloy at room and high temperatures. Zafari et al. disclose 
that, increase of load and speed results in severe changes in wear. Zafari et al. (2014) also scrutinized the role of rare earth additions (lanthanum) in high temperature wear behavior. At temperature range $100-200^{\circ} \mathrm{C}, \mathrm{AZ} 91$ alloy shows severe wear while RE containing alloy shows much lower wear rate. Labib et al. (2016) have used $\mathrm{SiC}$ particle as reinforcing phase in magnesium matrix and studied wear behavior at room and high temperature. Labib et al. discloses that use of ceramic based $\mathrm{SiC}$ particle possess significant less wear rate compared to pure magnesium at high temperatures $\left(100-200^{\circ} \mathrm{C}\right)$. Accordingly in the current study tungsten carbide (WC) nanoparticles are considered because of its high hardness $(1400 \mathrm{HV})$, good shock absorption capability, high melting point, noteworthy oxidation resistance etc (Pal et al., 2018). Recently, Karuppusamy et al. (2019) have examined magnesium based nanocomposites having WC as reinforcement and studied wear behavior at cryogenic domain. Banerjee et al. (2019) have studied tribological behavior of Mg-WC nanocomposites at different temperatures. Praveenkumar et al. (2019) fabricated Mg-WC composites and evaluated mechanical as well as tribological properties at room temperature.

It is well-known that nano-particles are susceptible to agglomeration; accordingly, cautious selection of synthesis technique is solicited. Recent literatures show that metal matrix nanocomposites (MMNC) are efficiently and economically synthesized by ultrasonic treated stir-casting technique. Several ceramic particles i.e. $\mathrm{Al}_{2} \mathrm{O}_{3}, \mathrm{CNT}, \mathrm{SiC}, \mathrm{ZnO}$ are used to develop $\mathrm{Mg}-\mathrm{MMNC}$ using ultrasonic treated stir-casting technique (Nguyen et al., 2015; Erman et al., 2012; Selvam et al., 2014; Aung et al., 2010). In this process electrical energy having high frequency is employed to form mechanical vibrations in melt and small microscopic bubbles are generated. Further these bubbles implode and produce shock waves as well as intense heating. These shock waves and intense heating helps to break clusters of nanoparticles (Banerjee et al., 2019).

Recently, Nguyen et al. (2015) synthesized $\mathrm{Mg}-\mathrm{Al}_{2} \mathrm{O}_{3}$ and found excellent wear behavior at high load and speeds. Habibnejad-Korayem et al. (2010) have reported superior wear behavior of $\mathrm{Mg}-\mathrm{Al}_{2} \mathrm{O}_{3}$. Kaviti et al. (2018) fabricated $\mathrm{Mg}$-BN nanocomposites and examined wear behaviour at different load and speed. Labib et al. (2016) synthesized $\mathrm{Mg}$-SiC composites and investigated wear behavior at temperature range of $25-250^{\circ} \mathrm{C}$ at different loads. Significantly lower wear rate is reported for composites at elevated temperatures. Gopal et al. (2017) have developed Mg-CRT-BN composites and reported the contribution of size \& wt. \% on tribological characteristics. Banerjee and Sutradhar (2018) have statistically optimized tribological process parameters of Mg-Gr-WC using RSM. Girish et al. (2016) have used Taguchi methodology to investigate wear behavior $\mathrm{Mg}-\mathrm{SiC}-\mathrm{Gr}$ composites. Available literature discloses that studies on optimization of elevated temperature wear behaviour of $\mathrm{Mg}-\mathrm{WC}$ nanocomposites are not available. Present study uses Taguchi method based $\mathrm{L}_{27} \mathrm{OA}$ to find optimal parameter condition of minimized wear rate. For this purpose wt.\% of reinforcement, applied load and elevated temperatures are taken as input factors while three levels of every factor are considered. Significant parameters and interactions are found by ANOVA analysis. Finally adequacy of the model is successfully verified by confirmation test.

\section{Experimental Scheme}

In current investigation, AZ31 alloy is observed as base material because of excellent castability, good formability, low density and high elastic modulus. Elemental details of AZ31 is presented in Table 1. Tungsten carbide nanoparticles (HW Nano, K510) with average size $80 \mathrm{~nm}$ are chosen as reinforcement. Details of WC are given in Table 2. For this study 1, 1.5 and 2 wt.\% of reinforcements are reinforced with AZ31 magnesium alloy.

Table 1. Elemental details of AZ31

\begin{tabular}{ccccccc}
\hline Element & $\mathrm{Si}$ & $\mathrm{Mn}$ & $\mathrm{Al}$ & $\mathrm{Fe}$ & $\mathrm{Zn}$ & $\mathrm{Mg}$ \\
\hline Wt. \% & 0.10 & 0.28 & 3.20 & 0.22 & 1.20 & Balance \\
\hline
\end{tabular}

An expressly designed stir casting furnace (SWAMEQUIP, Chennai) is used to develop magnesium metal matrix nanocomposites (MMNC). Illustrated representation of the main furnace and other particulars are furnished in Figure 1. This furnace has several attachments like particle preheating attachment, mechanical stirrer, inert gas supply, bottom pouring system, die pre-heating set up, ultrasonic vibrator. Primarily, required extent of AZ31 alloy is inserted into the main crucible and heated at $750^{\circ} \mathrm{C}$. Meanwhile, desired proportion of tungsten carbide nanoparticles are weighted and brought into the particle heating chamber and die heating rod is put down inside the split type die to foreheat it. After a certain time a drop in melt temperature is noticed which yields that magnesium alloy inside the crucible is fully melted. Then the stirrer is dip into the melt and stirring is started at high speed. As a result vortex is created. Preheated nanoparticles are then injected continuously into the melt. Mechanical stirring is stopped after completion of particle injection. Very high

Design of experiment analysis of elevated temperature wear of Mg-WC nano-composites (Sudip Banerjee) 
frequency ultrasonic cavitation $(20 \mathrm{KHz})$ is produced inside the melt by use of ultrasonic horn. Ultrasonic vibration breaks the particle cluster and helps to achieve uniform distribution of reinforced particles. Finally the die is kept into vacuum arrangement which is put under bottom pouring hole and composite slurry is drained in vacuum condition $\left(10^{-2} \mathrm{mbar}\right)$. Total experiment is conducted under argon gas environment to protect the system from oxidation. After a certain time the melt is solidified and solidified bar is pull out from the die. Then parting, milling, shaping, turning and grinding is done to develop desired sample $(6 \mathrm{~mm} \mathrm{dia}$., $30 \mathrm{~mm}$ length). Parameteric arrangements of fabrication are tabulated in Table 3.

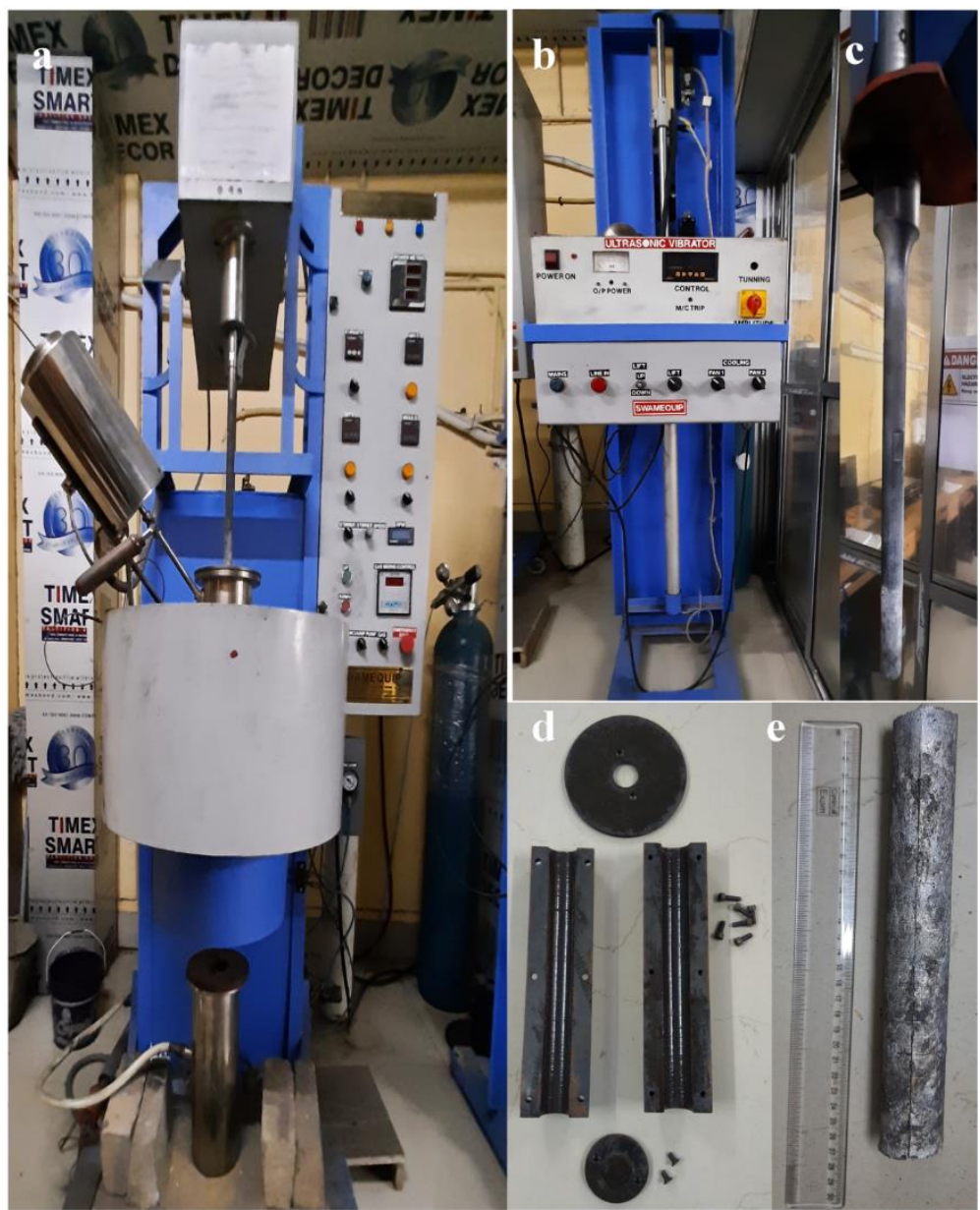

Figure 1. Pictorial view of the furnace (a) Main furnace, (b) Ultrasonic vibrator, (c) Ultrasonic horn, (d) split-type die, (e) As-cast bar

Table 2. Details of WC powder

\begin{tabular}{ll}
\hline Parameter & Details \\
\hline Particle Size & $80 \mathrm{~nm}$ \\
Purity of WC & $99.9 \%$ \\
Form & Hexagonal \\
Specific surface area (SSA) & $3-8 \mathrm{~m}^{2} / \mathrm{g}$ \\
Color & Black \\
Composition of WC & W-93.8\% \\
& C-6.1\% \\
\hline
\end{tabular}


Table 3. Parameter context during experimentation

\begin{tabular}{ll}
\hline Parameters & Value \\
\hline Temperature of Furnace & $750^{\circ} \mathrm{C}$ \\
Material of Stirrer & Stainless steel \\
Mechanical stirring time & $8-10$ minutes \\
Blade Angle & $45^{\circ}$ \\
Pre-heating temperature of reinforcement & $300^{\circ} \mathrm{C}$ \\
Ultrasonic frequency & $20 \mathrm{KHz}$ \\
Duration of Ultrasonic vibration & $3-5 \mathrm{minutes}$ \\
Die Dimension & $\Phi 50 \mathrm{~mm} \times 300 \mathrm{~mm}$ (Split type) \\
\hline
\end{tabular}

In current study hypothesis of Taguchi robust design based parameter outline is employed so that optimality for minimized wear rate of fabricated materials can be engineered. Parametric design helps to decide requisite orthogonal array. Concept of orthogonal array decides preferable quantity of experiments relying on quantity of input factors and their levels. Accordingly, $\mathrm{L}_{27} \mathrm{OA}$ is chosen to cut down total amount of experiments. Idea of signal to noise ratio ( $\mathrm{S} / \mathrm{N}$ ratio) is employed to distinguish role of input factors on output factor. Aim of this investigation is to minimize wear rate hence lower the better principle of $\mathrm{S} / \mathrm{N}$ ratio is employed. Significant process parameters and interactions of this study are found by performing analysis of variance (ANOVA). In this study, three input parameters having three levels each are taken. Considered factors and levels are tabulated in Table 4.

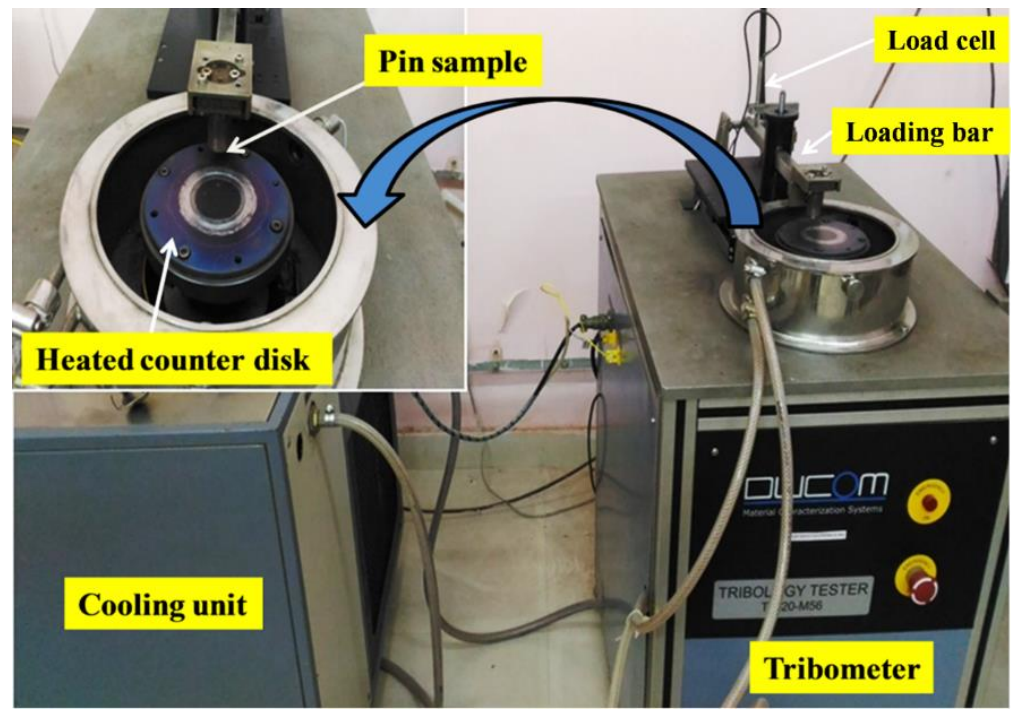

Figure 2. Pictorial view of tribotester

Table 4. Input factors and levels

\begin{tabular}{ccccc}
\hline Factors & Units & Level 1 & Level 2 & Level 3 \\
\hline Wt.\% & $\%$ & 1 & 1.5 & 2 \\
Temperature & ${ }^{\circ} \mathrm{C}$ & 100 & 150 & 200 \\
Load & $\mathrm{N}$ & 20 & 30 & 40 \\
\hline
\end{tabular}

Experimental results of elevated temperature wear behavior of $\mathrm{Mg}-\mathrm{WC}$ nanocomposites are achieved by using a pin-on-disc tribotester (TR-20-M56, DUCOM). Pictorial view of trobotester is shown in Figure 2. Hardened EN 31 disc $(\Phi=115 \mathrm{~mm}, \mathrm{t}=8 \mathrm{~mm})$ having high hardness $(58-62 \mathrm{HRC})$ is considered as counterface system to assure happening of wear only in pin surface. Pin samples are vertically placed on the disc using stationary fixture. Counter disc has rotary motion and the pin surface rub against the counter disc. The counter

Design of experiment analysis of elevated temperature wear of Mg-WC nano-composites (Sudip Banerjee) 
face disc is heated by $15 \mathrm{KVA}$ induction heating system at the time of experimentation. Wear tests are conducted according to ASTM G99-05. Experiments are carried out for $10 \mathrm{~min}$ at different temperature and load while sliding speed is fixed at $0.4 \mathrm{~m} / \mathrm{s}$. Pin samples are weighted before and after test to find the mass loss using digital weighing balance (Afcoset, 182A) to calculate wear rate.

\section{Results \& Discussion}

Elevated temperature wear behavior of produced nanocomposites is statistically analyzed by performing $\mathrm{S} / \mathrm{N}$ ratio analysis, ANOVA analysis and validation test. Genichi Taguchi, founder of Taguchi methodology, suggested choosing $\mathrm{S} / \mathrm{N}$ ratio analysis in lieu of simple average method while studying experimental results to predict optimal condition. Main advantage of $\mathrm{S} / \mathrm{N}$ ratio analysis is that it is capable of studying variability of experimental results. Accordingly $\mathrm{S} / \mathrm{N}$ ratio analysis of experimental data is carried out in this study. As wear rate is needed to be minimized lower the better criterion of $\mathrm{S} / \mathrm{N}$ ratio analysis is considered in this study. $\mathrm{S} / \mathrm{N}$ ratios of experimental data are calculated by following formula $(n=$ no. of observations, $y=$ examined data):

$$
S / N=-10 \log \left(1 / n \sum y^{2}\right)
$$

Design of experiment and interrelated $\mathrm{S} / \mathrm{N}$ ratios are noted in Table 5. Mean value of the $\mathrm{S} / \mathrm{N}$ ratio of all level of each factor is presented in response table (Table 6). Total mean value of $\mathrm{S} / \mathrm{N}$ ratio is found to be -8.693 dB. Table 6 also presents delta value of every process parameter. Depending on the delta value, process parameters are ranked which helps to decide the influence of that process parameter on the response variable. Table 6 shows that wt.\% of WC (A) is ranked as 1, temperature (B) is ranked as 2 and applied load (C) is ranked as 3. Hence, $\mathrm{A}$ is the most influencing parameter followed by $\mathrm{B}$ and $\mathrm{C}$.

Main effect curve endorses to analyze the influence of input factors on output variable. It also stimulates to find the optimal condition for output parameter. Figure 3 shows the main effect plot of this study. It is well known that nature of the plots explain the effect of the parameter and their levels. Parameter showing highest inclination proves to be of greater importance while parameter having gentle slope considered to be of less importance. Figure 3 shows that plot of parameter A has highest inclination followed by slope of parameter B and parameter C. Hence parameter A has highest importance while B and C have moderate importance. It is evident from Figure 3 that at level 3, parameter A has maximal S/N ratio while parameter B and parameter $\mathrm{C}$ both has maximal $\mathrm{S} / \mathrm{N}$ ratio value at level 1 . Thus, optimality for minimum wear rate is A3B1C1, i.e. $2 \mathrm{wt}$. $\%$ of $\mathrm{WC}, 100^{\circ} \mathrm{C}$ temperature and $20 \mathrm{~N}$ load. Figure 4 presents the both way interaction plot of this study. In interaction plot, non-parallel lines yields occurence of interaction and intersecting lines yields occurence of strong interaction. In Figure 4, non-parallel lines are present for all three cases which disclose that interaction is present for all three cases of this study.

Analysis of variance is a statistical model to figure out the significant process parameters and interactions which majorly influence total variance of experimental data. Table 7 shows the results of ANOVA analysis of this study. ANOVA table consists of sum of square (SS), mean square (MS), F-ratio, P factor and percentage contribution of each factor. F-ratio values justify the significance of the parameter or interaction. Parameter having higher F-ratio value has higher possibility to be significant. In this study, A has highest F-ratio value followed by $\mathrm{B}$ and $\mathrm{C}$ which suggest that wt.\% of $\mathrm{WC}(\mathrm{A})$ is utmost significant fator while temperature (B) and load $(C)$ are moderately significant. Among the interacting parameters, $(A \times B)$ has moderate significance. $\mathrm{P}$ values of $\mathrm{A}, \mathrm{B}, \mathrm{C}$ and $(\mathrm{A} \times \mathrm{B})$ are below 0.005 , which yields significance of these parameters. Table 7 also shows that $\mathrm{A}$ has $43.135 \%$ contribution while $\mathrm{B}, \mathrm{C}$ and $(\mathrm{A} \times \mathrm{B})$ have $26.623 \%, 19.037 \%$ and $5.639 \%$ contribution respectively.

Coefficient of determination value for the present study is $98.97 \%$. Adequacy of the present model is verified by the normal probability plot (NPP) which is presented in Figure 5. NPP correlate the forecasted values of the system with experimental data. Figure 5 yields that experimental dossier approximately follows a straight line that verifies the adequacy of the system. Similar result was seen in the study of Karuppusamy et al. (2019).

Finally confirmation test is implemented to compare the initial condition with optimal condition so that improvement in final optimal result can be understood. Optimal level is predicted using following equation:

$$
\bar{\eta}=\eta_{m}+\sum_{i=1}^{0}\left(\overline{\eta_{i}}-\eta_{m}\right)
$$

where, $\eta_{\mathrm{m}}=$ total mean data, $\eta_{\mathrm{i}}=$ mean data at optimal level, $\mathrm{o}=$ number of selected input factors which significantly affect output response. 
Table 5. Design of experiment and corresponding $\mathrm{S} / \mathrm{N}$ ratios

\begin{tabular}{|c|c|c|c|c|}
\hline $\begin{array}{l}\text { Run } \\
\text { order }\end{array}$ & Wt.\% & Temperature & Load & SNRA \\
\hline 1 & 1 & 100 & 20 & -7.47295 \\
\hline 2 & 1 & 100 & 30 & -7.82223 \\
\hline 3 & 1 & 100 & 40 & -8.41891 \\
\hline 4 & 1 & 150 & 20 & -9.02652 \\
\hline 5 & 1 & 150 & 30 & -9.41703 \\
\hline 6 & 1 & 150 & 40 & -12.8966 \\
\hline 7 & 1 & 200 & 20 & -11.0485 \\
\hline 8 & 1 & 200 & 30 & -11.4598 \\
\hline 9 & 1 & 200 & 40 & -16.277 \\
\hline 10 & 1.5 & 100 & 20 & -7.12052 \\
\hline 11 & 1.5 & 100 & 30 & -7.276 \\
\hline 12 & 1.5 & 100 & 40 & -7.64394 \\
\hline 13 & 1.5 & 150 & 20 & -8.47147 \\
\hline 14 & 1.5 & 150 & 30 & -9.07554 \\
\hline 15 & 1.5 & 150 & 40 & -11.9605 \\
\hline 16 & 1.5 & 200 & 20 & -10.5294 \\
\hline 17 & 1.5 & 200 & 30 & -10.5113 \\
\hline 18 & 1.5 & 200 & 40 & -14.9187 \\
\hline 19 & 2 & 100 & 20 & -4.665 \\
\hline 20 & 2 & 100 & 30 & -5.31993 \\
\hline 21 & 2 & 100 & 40 & -6.8524 \\
\hline 22 & 2 & 150 & 20 & -3.23335 \\
\hline 23 & 2 & 150 & 30 & -4.91519 \\
\hline 24 & 2 & 150 & 40 & -6.61639 \\
\hline 25 & 2 & 200 & 20 & -6.08119 \\
\hline 26 & 2 & 200 & 30 & -6.54309 \\
\hline 27 & 2 & 200 & 40 & -9.13339 \\
\hline
\end{tabular}

Table 6. Response table

\begin{tabular}{cccc}
\hline Level & Wt\% & Temperature & Load \\
\hline 1 & -10.427 & -6.955 & -7.517 \\
2 & -9.723 & -8.401 & -8.038 \\
3 & -5.929 & -10.722 & -10.524 \\
Delta & 4.498 & 3.768 & 3.008 \\
Rank & 1 & 2 & 3 \\
\hline
\end{tabular}




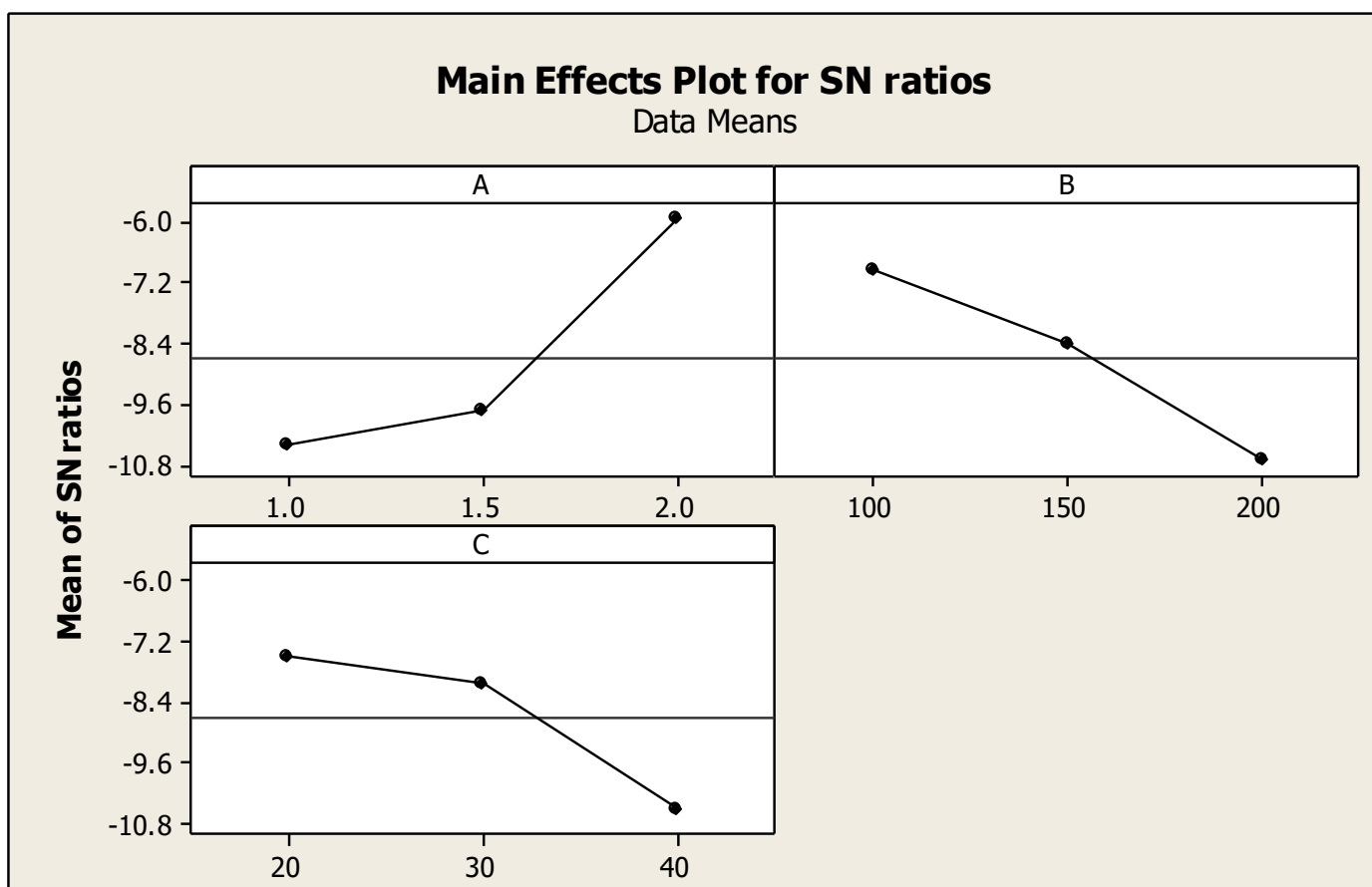

Signal-to-noise: Smaller is better

Figure 3. Main effect plot

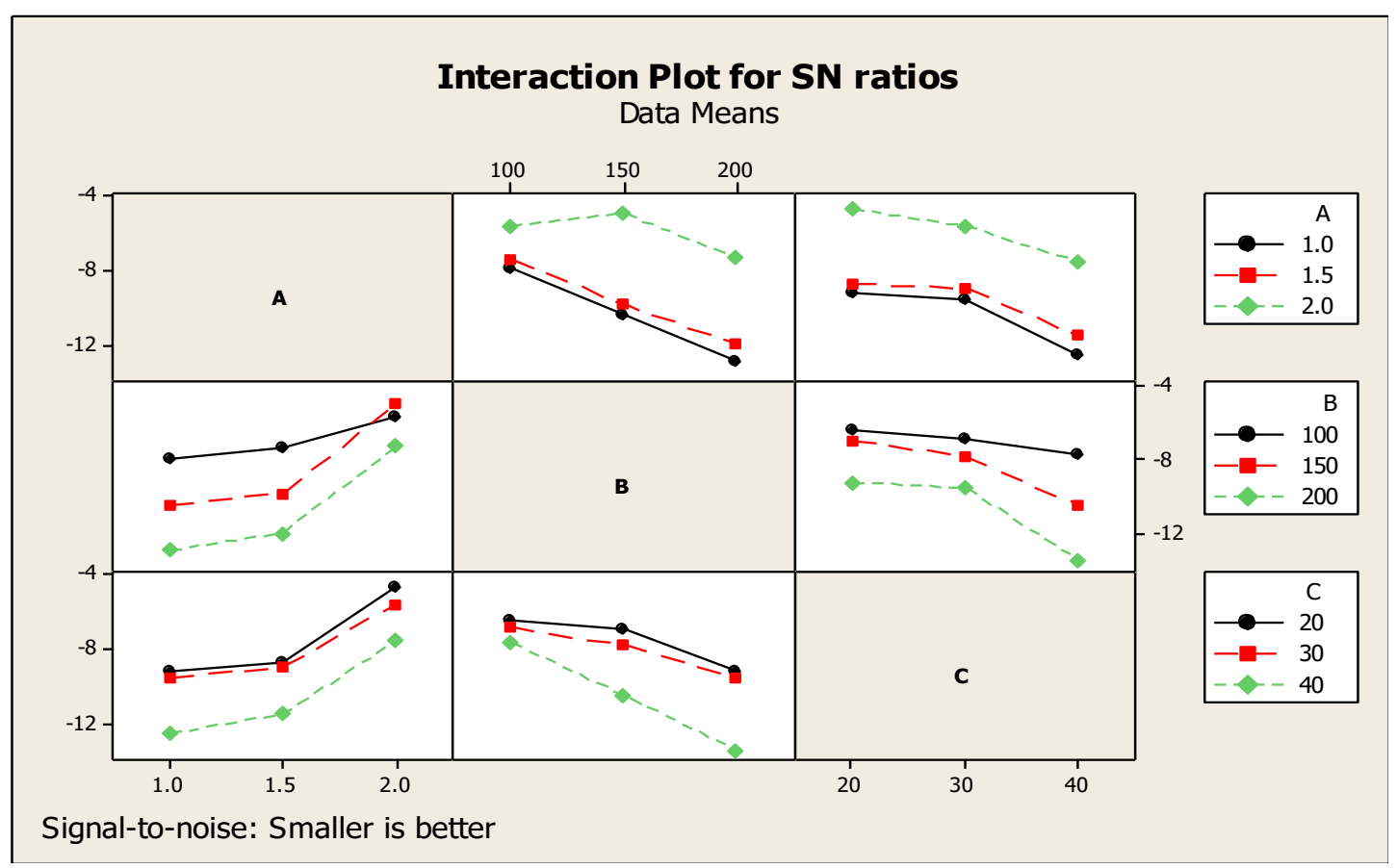

Figure 4. Interaction plot 


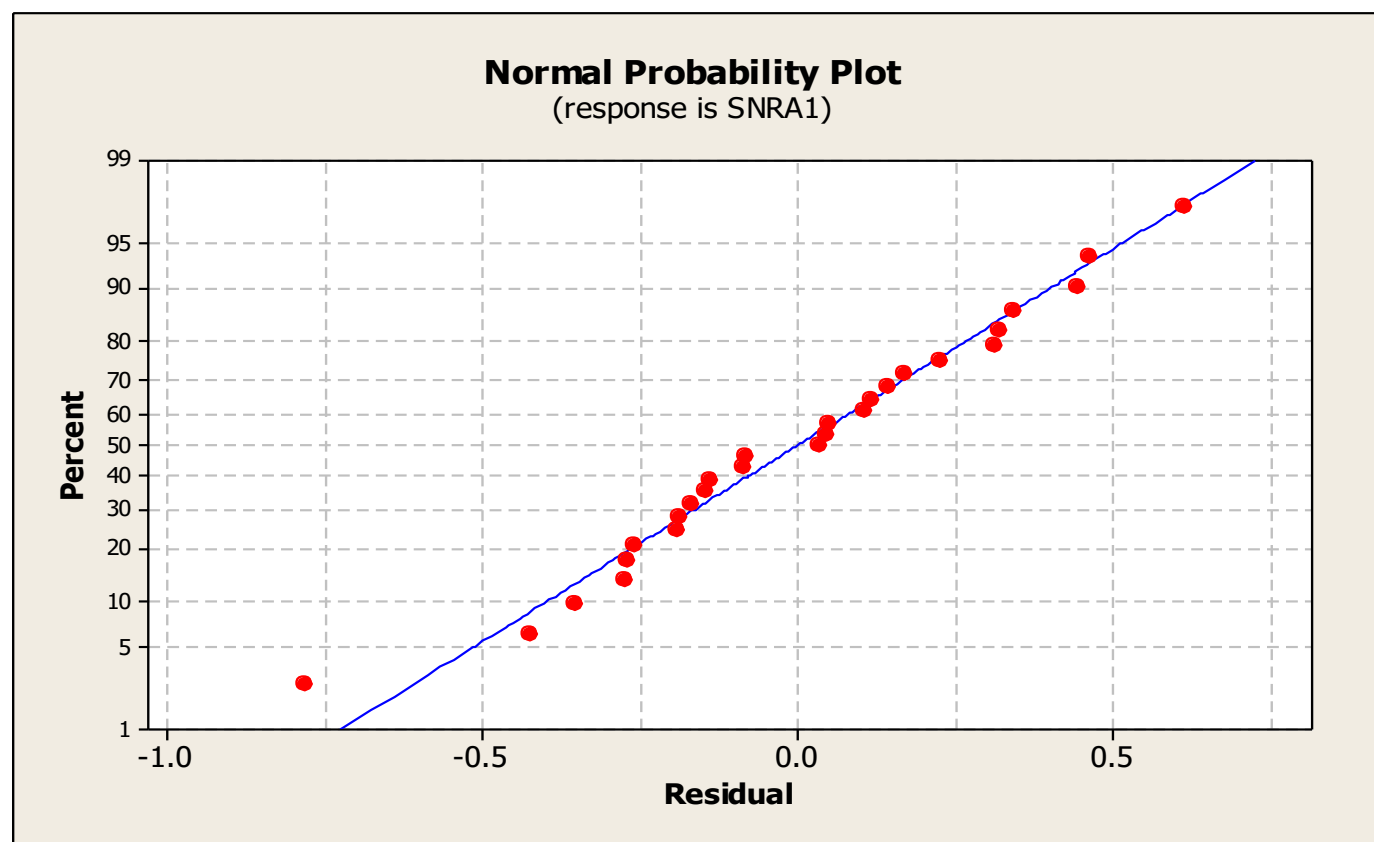

Figure 5. Normal probability plot

Table 7. ANOVA table

\begin{tabular}{ccccccc}
\hline Source & DF & Adj SS & $\begin{array}{c}\text { Adj } \\
\text { MS }\end{array}$ & $\begin{array}{c}\text { F- } \\
\text { Value }\end{array}$ & P-Value & \%Contribution \\
\hline Wt.\% & 2 & 105.360 & 52.680 & 167.23 & 0.000 & 43.135 \\
Temp. & 2 & 65.030 & 32.515 & 103.22 & 0.000 & 26.623 \\
Load & 2 & 46.500 & 23.250 & 73.81 & 0.000 & 19.037 \\
Wt.\%*Temp. & 4 & 13.774 & 3.444 & 10.93 & 0.003 & 5.639 \\
Wt.\%*Load & 4 & 0.970 & 0.243 & 0.77 & 0.574 & 0.397 \\
Temp.*Load & 4 & 10.102 & 2.526 & 8.02 & 0.007 & 4.136 \\
$\quad$ Error & 8 & 2.520 & 0.315 & & & \\
$\quad$ Total & 26 & 244.258 & & & & 100.000 \\
\hline S & R-sq & R-sq(adj.) & & & \\
0.561256 & $98.97 \%$ & $96.65 \%$ & & & & \\
\hline
\end{tabular}

Table 8. Confirmation table

\begin{tabular}{cccc}
\hline \multirow{2}{*}{ Initial Condition } & \multicolumn{2}{c}{ Optimal condition } \\
\cline { 3 - 4 } & & Prediction & Experimentation \\
\hline Level & A2B2C2 & A3B1C1 & A3B1C1 \\
Wear & 2.843 & & 1.711 \\
S/N ratio & -9.076 & -3.015 & -4.665 \\
(dB) & & & \\
\hline
\end{tabular}

Table 8 reveals the details of the confirmation test of this study. It is found that $\mathrm{S} / \mathrm{N}$ ratio is improved by $4.411 \mathrm{~dB}(48.60 \%)$ than the initial condition. That much improvement is very significant. 


\section{Conclusion}

In this investigation, $\mathrm{Mg}$-WC nanocomposites are synthesized by ultrasonic treatment assisted stir-casting technique. Taguchi robust design is successfully employed to optimize process parameters (wt.\% of reinforcement, temperature and load) to minimize wear rate of nanocomposites. Significant process parameters and interactions of this study are found by performing analysis of variance (ANOVA). Adequacy of the present model is verified by the normal probability plot (NPP). Confirmation test is implemented to compare the initial condition with optimal condition so that improvement in final optimal result can be understood. From this statistical investigation, subsequent interpretetion are made:

- Optimality of minimum wear rate is $2 \mathrm{wt} . \%$ of $\mathrm{WC}, 100^{\circ} \mathrm{C}$ temperature and $20 \mathrm{~N}$ load (A3B1C1).

- Wt.\% of WC is utmost notable factor while temperature and load are moderately significant. Among the interacting parameters, interaction between wt.\% of $\mathrm{WC} \&$ temperature $(\mathrm{A} \times \mathrm{B})$ has moderate significance. Wt.\% WC (A) has $43.135 \%$ contribution while temperature (B), load (C) and interaction between wt.\% of WC $\&$ temperature $(\mathrm{A} \times \mathrm{B})$ have $26.623 \%, 19.037 \%$ and $5.639 \%$ contribution respectively.

- Coefficient of determination value for the present study is $98.97 \%$. Adequacy of the present model is verified by the normal probability plot (NPP).

- Confirmation test discloses that $\mathrm{S} / \mathrm{N}$ ratio at optimality is improved by $4.411 \mathrm{~dB}(48.60 \%)$ than the initial condition.

Acknowledgement: Authors admiringly appreciate the financial assistance of Smart Foundry-2020 (DST, GOI), Jadavpur University.

\section{References}

Aung, N. N., Zhou, W., Goh, C. S., Nai, S. M. L., \& Wei, J. (2010). Effect of carbon nanotubes on corrosion of Mg-CNT composites. Corrosion Science, 52(5), 1551-1553.

Avedesian, M. M., \& Baker, H. (Eds.). (1999). ASM specialty handbook: magnesium and magnesium alloys. ASM international.

Banerjee, S., \& Sutradhar, G. (2018). Study on Wear Behaviour of Mg-Gr-WC Nanocomposite Using Response Surface Methodology. Materials Today: Proceedings, 5(9), 17664-17673.

Banerjee, S., Poria, S., Sutradhar, G., \& Sahoo, P. (2019). Dry sliding tribological behavior of AZ31-WC nano-composites. Journal of Magnesium and Alloys, 7(2), 315-327.

Banerjee, S., Poria, S., Sutradhar, G., \& Sahoo, P. (2019). Tribological behavior of Mg-WC nanocomposites at elevated temperature. Materials Research Express, 6(8), $0865 \mathrm{c} 6$.

Banerjee, S., Poria, S., Sutradhar, G., \& Sahoo, P. (2019). Wear performance of Mg-WC metal matrix nanocomposites using taguchi methodology. Materials Today: Proceedings, 19, 177-181.

Erman, A., Groza, J., Li, X., Choi, H., \& Cao, G. (2012). Nanoparticle effects in cast Mg-1 wt\% SiC nanocomposites. Materials Science and Engineering: A, 558, 39-43.

Girish, B. M., Satish, B. M., \& Sarapure, S. (2016). Optimization of wear behavior of magnesium alloy AZ91 hybrid composites using taguchi experimental design. Metallurgical and Materials Transactions A, 47(6), 3193-3200.

Gopal, P. M., Prakash, K. S., Nagaraja, S., \& Aravinth, N. K. (2017). Effect of weight fraction and particle size of CRT glass on the tribological behaviour of Mg-CRT-BN hybrid composites. Tribology International, $116,338-350$.

Habibnejad-Korayem, M., Mahmudi, R., Ghasemi, H. M., \& Poole, W. J. (2010). Tribological behavior of pure Mg and AZ31 magnesium alloy strengthened by Al2O3 nano-particles. Wear, 268(3-4), 405-412.

Hirsch, J., \& Al-Samman, T. (2013). Superior light metals by texture engineering: Optimized aluminum and magnesium alloys for automotive applications. Acta Materialia, 61(3), 818-843.

Karuppusamy, P., Lingadurai, K., \& Sivananth, V. (2019). Influence of cryogenic treatment on as-cast AZ91+ 1.5 wt\% WC Mg-MMNC wear performance. In Advances in materials and metallurgy (pp. 185-197). Springer, Singapore.

Karuppusamy, P., Lingadurai, K., \& Sivananth, V. (2019). To study the role of WC reinforcement and deep cryogenic treatment on AZ91 MMNC wear behavior using multilevel factorial design. Journal of Tribology, 141(4).

Kaviti, R. V. P., Jeyasimman, D., Parande, G., Gupta, M., \& Narayanasamy, R. (2018). Investigation on dry sliding wear behavior of Mg/BN nanocomposites. Journal of Magnesium and Alloys, 6(3), 263-276. 
Labib, F., Ghasemi, H. M., \& Mahmudi, R. (2016). Dry tribological behavior of Mg/SiCp composites at room and elevated temperatures. Wear, 348, 69-79.

Nguyen, Q. B., Sim, Y. H. M., Gupta, M., \& Lim, C. Y. H. (2015). Tribology characteristics of magnesium alloy AZ31B and its composites. Tribology International, 82, 464-471.

Pai, B. C., Pillai, U. T. S., Manikandan, P., \& Srinivasan, A. (2012). Modification of AZ91 Mg alloys for high temperature applications. Transactions of the Indian Institute of Metals, 65(6), 601-606.

Pal, A., Poria, S., Sutradhar, G., \& Sahoo, P. (2018). Tribological behavior of Al-WC nano-composites fabricated by ultrasonic cavitation assisted stir-cast method. Materials Research Express, 5(3), 036521.

Praveenkumar, R., Periyasamy, P., Mohanavel, V., \& Ravikumar, M. M. (2019). Mechanical and Tribological Behavior of Mg-Matrix Composites Manufactured by Stir Casting. International Journal of Vehicle Structures \& Systems (IJVSS), 11(1).

Selvam, B., Marimuthu, P., Narayanasamy, R., Anandakrishnan, V., Tun, K. S., Gupta, M., \& Kamaraj, M. (2014). Dry sliding wear behaviour of zinc oxide reinforced magnesium matrix nano-composites. Materials \& Design, 58, 475-481.

Zafari, A., Ghasemi, H. M., \& Mahmudi, R. (2012). Tribological behavior of AZ91D magnesium alloy at elevated temperatures. Wear, 292, 33-40.

Zafari, A., Ghasemi, H. M., \& Mahmudi, R. (2014). An investigation on the tribological behavior of AZ91 and AZ91+ 3 wt\% RE magnesium alloys at elevated temperatures. Materials \& Design (1980-2015), 54, 544552. 